\title{
Decidualization is Impaired in Endometrial Stromal Cells from Uterine Rudiments in Mayer-Rokitansky-Küster-Hauser Syndrome
}

\author{
Sara Y. Brucker ${ }^{a, b}$ Simone Eisenbeis ${ }^{b}$ Juliana König ${ }^{a, b} \quad$ Melanie Lamy ${ }^{a, b}$ \\ Madhuri S. Salker ${ }^{b, c}$ Ni Zeng ${ }^{c}$ Harald Seeger ${ }^{a, b}$ Melanie Henes $^{a}$ \\ Dorit Schöller ${ }^{a}$ Birgitt Schönfisch ${ }^{b}$ Annette Staebler ${ }^{d}$ Florin-Andrei Taran ${ }^{a}$ \\ Diethelm Wallwiener ${ }^{\mathrm{a}}$ Katharina Ralla,b

\begin{abstract}
aDepartment of Women's Health, University of Tübingen, 'besearch Institute for Women's Health, University of Tübingen, 'Department of Internal Medicine III, University of Tübingen, dDepartment of Anatomic Pathology, Institute of Pathology and Neuropathology, University of Tübingen, Tübingen, Germany
\end{abstract}

\section{Key Words}

Müllerian agenesis - Müllerian aplasia - Congenital vaginal agenesis • Decidualization • Endometrium

\begin{abstract}
Background/Aims: Uterine rudiments from patients with Mayer-Rokitansky-Küster-Hauser syndrome (MRKHS) contain all tissues typically found in the uterus. Endometrium from the rudiments predominantly exhibits basalis-like features, and endometrial proliferative capacity in patients' epithelium and stroma is significantly lower. Methods: This single-center, prospective study conducted at a major German university hospital compared in-vitro decidualization in cultured ESCs from MRKHS patients and hysterectomy controls. Primary ESC cultures were established from both sources. Hormone-induced prolactin and IGFBP-1 secretion served as a measure of their ability to undergo decidualization in response to hormonal stimulation. Expression levels of 8 key marker genes of decidualization were also determined. Results: At day 9 , mean secretion of prolactin and IGFBP-1 was significantly reduced by $89.0 \%$ and $99.5 \%$, respectively, in MRKHS ESCs vs. hysterectomy controls, both indicating impaired decidualization of MRKHS ESCs. Key decidual markers confirmed impaired decidualization in MRKHS patients. Conclusion: Our results indicate that the ESCs from MRKHS patients lack hormone responsiveness as a potential sign of dysfunctional hormone receptor function, which may also play a role in the onset of MRKHS. Further studies are needed to corroborate our findings, directly address receptor function, and elucidate the role of other potential determinants of uterine development and adult function.




\section{Cellular Physiology Cell Physiol Biochem 2017;41:1083-1097

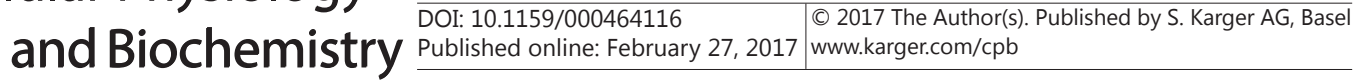 \\ Brucker et al.: Decidualization is Impaired in ESCs}

\section{Introduction}

Mayer-Rokitansky-Küster-Hauser (MRKH) syndrome (MRKHS) is a congenital uterovaginal malformation in which the normal embryonic development of the female internal genitalia is arrested during the first trimester, resulting in the partial or complete absence of the uterus and the upper two thirds of the vagina. In the majority of cases, a rudimentary uterus forms, consisting of two uterine remnants [1]. The remnants generally contain an intact myometrial layer and, in rare cases, a layer of endometrium [2, 3].

MRKHS occurs in two basic phenotypes; type 1 is characterized by isolated uterovaginal aplasia or hypoplasia whereas type 2 is additionally associated with renal, skeletal, or other malformations. The exact cause of this developmental disorder remains unknown despite extensive genetic studies. Candidate gene approaches have focused on genes involved in the development of the female reproductive tract or genes known to be associated with disorders with similar manifestations, e.g., PAX2, WT1, GALT, HOXA7-13, PBX1, AMH, and the WNT gene family [4-12]. However, so far no common genetic variations have been found in a larger group of MRKHS patients. We therefore studied the rudimentary organ itself and demonstrated in earlier histological and immunohistochemical work that the proliferative capacity of endometrium was significantly reduced in uterine rudiments from MRKHS patients [2]. In a first-ever study using combined whole-genome expression and methylation to investigate the potential role of epigenetic factors, we found, inter alia, that hormone receptors were overexpressed in uterine rudiments from MRKHS patients [13]. The observed local overexpression of estrogen receptor 1 (ESR1) and progesterone receptor (PGR) may have resulted from a positive feedback loop to compensate for functional restrictions, as proliferation capacity is significantly reduced.

Moreover, increased ESR1 expression may have resulted in aberrant activation of the anti-Müllerian hormone (AMH) promoter during embryonic development of the female reproductive tract and, ultimately, regression of the Müllerian ducts [13], thus constituting a functional, local cause for the observed absence of the uterine organ. This hypothesis is supported by our histological and immunohistochemical analyses of the structure of uterine rudiments from MRKHS patients [2]. This earlier work showed that the endometrial layer in the uterine rudiments predominantly exhibited basalis-like features, but revealed no significant quantitative difference compared with healthy control tissue regarding the expression of both ESR1 and PGR in the endometrium and myometrium [2].

Quantitative or functional deficiency of PGR or ESR1 have been suggested as causes of MRKHS via the effect of maternal hormones on the embryo [14], as women with the disorder have a normal female karyotype, functioning ovaries, normal sex hormone levels, and normal female secondary sexual characteristics [15-17]. Hence, besides the developmental anomaly of the uterus, all other estrogen and progesterone-dependent tissues (e.g. the breast) are normally developed in women with MRKHS. And still, during puberty, even in the presence of normal blood hormone levels, usually no further development or cycle dependent differentiation occurs in uterine rudiments or their endometrial tissue (e.g. no development of relevant hematometra). This supports the above hypothesis of a local deficiency in hormone receptors.

Decidualization occurs during the secretory phase of the menstrual cycle and involves the estrogen-primed and progesterone-induced differentiation of endometrial fibroblasts into secretory, or decidual cells $[18,19]$. Prolactin (PRL) and insulin-like growth factor binding protein-1 (IGFBP-1) are key secretory markers of this differentiation process [20-24].

Against this background, we conducted the first study of its kind to possibly indirectly test ESR1 and PGR function in MRKHS by investigating primary endometrial stromal cells (ESCs) cultured from MRKHS uterine rudiments for their ability to efficiently undergo estrogen and progesterone-induced in-vitro decidualization in comparison with ESCs from non-MRKHS hysterectomy controls undergoing hysterectomy for benign disease. Prolactin and IGFBP-1 secretion by cultured ESCs served as a measure of hormone responsiveness 


\section{Cellular Physiology Cell Physiol Biochem 2017;41:1083-1097

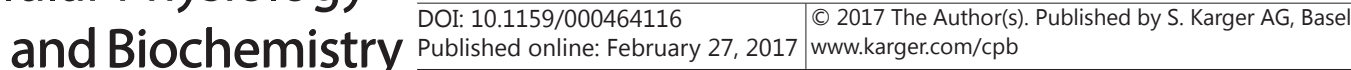 \\ Brucker et al.: Decidualization is Impaired in ESCs}

and quantitative real-time polymerase chain reaction (qRT-PCR) studies were performed to measure induction of key decidual genes upon hormone treatment.

\section{Materials and Methods}

Study design

This was a single-center, prospective, comparative in-vitro decidualization study of cultured ESCs from MRKHS patients and hysterectomy controls. The study was conducted at Tübingen University Women's Hospital and the Center for Rare Female Genital Malformations, a division of the Research Institute for Women's Health, Department of Women's Health, University of Tübingen, Germany, between July 2013 and January 2015.

\section{Ethical approval}

Ethical approval was obtained in advance from the Ethics Committee of the University of Tübingen (approvals 28/2008B01 and 205/2014B01). All study participants gave their prior written informed consent.

\section{Patients and tissues}

Uterine rudiments were removed from 37 MRKHS patients during laparoscopically assisted creation of a neovagina. Out of 43 rudiments collected and examined for the presence of endometrium, only 11 rudiments from 8 different MRKHS patients (mean age (SD), 24.5 (9.7) years) yielded sufficient endometrial tissue for ESC cultivation. For use as controls, endometrial tissue was obtained from 10 premenopausal nonMRKHS control patients (aged 43.0 (3.9) years) undergoing hysterectomy for benign indications. Premenopausal status was ascertained by female hormone profile or a detailed menstrual history. Before surgery, the controls had regular menstrual cycles and no relevant secondary diagnoses (in particular, no adenomyosis, endometriosis, or functional ovarian cysts), and all except one had proven fertility as evidenced by at least one pregnancy and delivery.

MRKHS patients' and controls' cycle phases were determined by hormone profiles one day before surgery. Cycle phase 1 (the proliferative phase) was defined by progesterone levels $<2.5 \mathrm{ng} / \mathrm{mL}$, whereas cycle phase 2 (the secretory phase) was defined by progesterone levels $>5 \mathrm{ng} / \mathrm{mL}$ and a $\mathrm{LH} / \mathrm{FSH}$ ratio $>1.5$, in accordance with our central laboratory's standards.

In the case of four controls for whom no hormone profiles were available the cycle phase was determined by taking a detailed menstrual history.

\section{Endometrial stromal cell culture}

After histological evaluation, endometrial tissue was scraped off the underlying myometrium of the uterine rudiment or control uterus using a scalpel. The harvested tissue was immediately transferred to a petri dish under sterile conditions. ESCs were isolated and cultivated according to Fluhr (personal communication, 2013 and [25]). Briefly, minced endometrial tissue was digested for 1 hour at $37^{\circ} \mathrm{C}$ in $0.5 \%$ collagenase (Biochrom, Berlin, Germany) in GIBCO $®$ Dulbecco's Modified Eagle Medium: Nutrient Mixture F-12 (DMEM/F-12) without phenol red (GIBCO/Life Technologies, Darmstadt, Germany). During incubation, the solution was pipetted up and down regularly until it was completely homogeneous. Enzymatic activity was subsequently stopped by adding the same volume of DMEM/F-12 without phenol red containing $10 \%$ fetal bovine serum to the suspension. Dispersed ESCs were isolated by subsequent filtration through a $40 \mu \mathrm{m}$ sieve (BD Falcon, Heidelberg, Germany). Epithelial cells were trapped while ESCs passed the sieve, yielding ESC cultures of $>90 \%$ purity. After filtration, the isolated ESCs were washed with phosphate buffered saline and cultured in DMEM/F-12 cell culture medium without phenol red containing 10\% charcoal-stripped fetal bovine serum (Life Technologies, Darmstadt, Germany), $5 \mu \mathrm{g} / \mathrm{mL}$ gentamicin (Biochrom, Berlin, Germany), and 1.1\% antibiotic antimycotic (GIBCO/Life Technologies) in $75 \mathrm{~cm}^{2}$ culture flasks (Greiner-Bio-One, Frickenhausen, Germany). After a short 30-min incubation, the culture medium was removed to eliminate the remaining blood cells and debris. Subsequently, the culture medium was changed every third day until the cells reached confluency. For optimal decidualization conditions it was important that the ESC cultures were passaged only once as higher-passage cultures reduced the cells' decidualizing potential [26]. 


\section{Cellular Physiology Cell Physiol Biochem 2017;41:1083-1097 \begin{tabular}{ll|l} 
and Biochemistry Published onlIne: February 27, 2017 & $\begin{array}{l}\text { (c) } 2017 \text { The Author(s). Published by S. Karger AG, Basel } \\
\text { www.karger.com/cpb }\end{array}$ \\
\hline
\end{tabular} \\ Brucker et al.: Decidualization is Impaired in ESCS}

\section{Immunohistochemistry}

Uterine rudiment tissue from each MRKHS patient was examined to establish whether hormone responsiveness in vivo was adequate and correlated with the resulting ESC cultures' ability to undergo proper decidualization. To this end, tissue sections from each MRKHS uterine rudiment were analyzed by immunohistochemistry as described in the following to determine the presence or absence of ESR1, PGR and the endometrial proliferation marker Ki-67. For quantification, immunoreactivity scores (IRSs) were calculated for each antigen according to a published method [27].

After removing ESCs for cell culture, the remaining rudiment tissue was fixed in formalin and embedded in paraffin. Subsequently, $4 \mu \mathrm{m}$ sections were cut from each block and stained with hematoxylin-eosin. Segments that showed evidence of a lumen-like structure after staining were further characterized by immunohistochemistry. To this end, $4 \mu \mathrm{m}$ sections were cut from selected tissue blocks and mounted on Superfrost $^{\mathrm{TM}}$ slides (Thermo Fisher Scientific, Walton, MA, USA). Immunohistochemistry (IHC) was performed using a Ventana Discovery automated immunostaining system and Ventana reagents (Ventana Medical Systems, Tucson, AZ, USA). Sections were deparaffinized with inorganic buffer. Depending on the protocols for the different antigens, sections were pretreated with ethylenediaminetetraacetic acid (EDTA) based buffer adjusted to pH 8.0 for ESR1, pH 6.0 for PGR, and pH 8.4 for Ki-67 (a marker of cellular proliferation). Heatinduced epitope retrieval (HIER) was performed for all antigens before the primary antibody was applied and incubated for one hour at room temperature (monoclonal rabbit anti-human estrogen receptor, clone SP1, DCS Innovative Diagnostik-Systeme, Hamburg, Germany, dilution 1:100, antibody diluent Zytomed Systems, Berlin, Germany; monoclonal rabbit anti-human progesterone receptor, clone SP2, DCS Innovative Diagnostik-Systeme, Hamburg, Germany, dilution 1:150, antibody diluent DCS diluent; monoclonal mouse anti-human Ki-67 antigen, clone MIB-1, M7240, Dako Cytomation, Glostrup, Denmark, dilution 1:200, antibody diluent Zytomed Systems). All stains were performed using a biotinylated detection kit containing diaminobenzidine and horseradish peroxidase (DABMap Kit Ventana). The slides were counterstained with hematoxylin and Blueing Reagent (Roche 760-2021), washed and dehydrated with a graded ethanol series (40\%, 70\%, 96\%), and finally covered with Cytoseal ${ }^{\mathrm{TM}}$ (Thermo Fisher Scientific, Walton, MA, USA). Nonexpressing tissues on the slides were used as an internal negative control (e.g. small vessels for hormone receptors and non-proliferating myometrium for Ki-67). In addition, staining protocols omitting the primary antibody steps were used as negative controls.

\section{Interpretation of immunostains}

The ESR1 and PGR immunostains were evaluated using a semi-quantitative immunoreactivity scoring (IRS) system [27]. In brief, a score of 0-3 was given for nuclear stain intensity and then multiplied with a second score of $0-4$ for the percentage of positive cells (score 0 for $0 \%, 1$ for $1-10 \%, 2$ for $11-50 \%, 3$ for $51-80 \%$, and 4 for $81-100 \%$ positive cells), yielding an overall score of $0-12$.

MIB-1 (antibody against Ki-67): The percentage of positive nuclei was estimated by evaluating at least 100 cells in one continuous area in the respective compartment of the specimen.

\section{Immunofluorescent staining}

ESC cultures were characterized and their purity and composition verified by immunofluorescent staining following standard protocols. ESC culture purity and composition were determined by staining with the ESC marker CD10 (monoclonal mouse CD10 antibody, unconjugated, clone 56C6, DAKO M7308; Dako, Hamburg, Germany) diluted 1:100, the epithelial cell marker pancytokeratin (monoclonal mouse pancytokeratin antibody, clone C11-FITC, GTX Genetex 11212; GeneTex, Irvine, CA, USA) diluted 1:200, and the smooth muscle cell marker actin for myometrial cells (monoclonal mouse smooth muscle actin antibody, unconjugated, clone 1A4, DAKO M0851) diluted 1:200. In addition, the presence of hormone receptors was determined using the ESR1 antibody (monoclonal mouse, unconjugated, clone 1D5, DAK0 M7047) diluted 1:50, and the progesterone receptor antibody (monoclonal mouse, unconjugated, clone PgR 636, DAKO M3569) diluted 1:50. Immunofluorescent stainings were evaluated using a Zeiss Axioplan 2 microscope and the AxioVision software release 4.8.2 (Carl Zeiss Microscopy, Jena, Germany).

Determination of in-vitro decidualization

After reaching confluence, ESC cultures were released from the culture flasks using 0.05\% trypsinEDTA (GIBCO/Life Technologies) and seeded into 24-well plates at 100,000 cells/well. Depending on the 


\section{Cellular Physiology Cell Physiol Biochem 2017;41:1083-1097

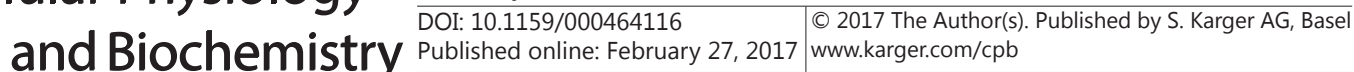

amount of endometrial tissue harvested from MRKH rudiments and the resulting ESC yield, experiments were performed at least in duplicate or in quadruplicate, which was standard for the controls. Decidualization in vitro was induced by incubating ESCs in cell culture medium containing $30 \mathrm{nmol} / \mathrm{L} 17 \beta$-estradiol (Sigma-Aldrich, Munich, Germany) and $1 \mu \mathrm{mol} / \mathrm{L}$ progesterone (Sigma-Aldrich) for 9 days. Estrogen and progesterone were dissolved in ethanol to a final concentration of $<0.1 \%$ in the cell culture medium. Cell culture medium containing estrogen and progesterone was renewed every third day. To determine spontaneous baseline prolactin secretion, each culture was accompanied by a parallel internal control culture that was incubated under the same conditions but without hormonal treatment. Decidualization of hormonetreated and untreated ESC control cultures was assessed at days $0,3,6$, and 9 by measuring prolactin and IGFBP-1 secretion into the supernatants using an enzyme-linked immunosorbent assay (ELISA; Human Prolactin DuoSet $\AA$, DY682, R\&D Systems and Human IGFBP-1 DuoSet $®$, DY871, R\&D Systems, Wiesbaden, Germany). The prolactin and IGFBP-1 assays had lower detection limits of $15.6 \mathrm{pg} / \mathrm{mL}$ and $31.3 \mathrm{pg} / \mathrm{mL}$, respectively and were both performed according to the manufacturer's instructions. Sample values were calculated from standard curves. All supernatant samples were assayed in duplicate and mean prolactin levels were calculated for each sample. To correct for spontaneous (i.e. non-induced) baseline secretion of prolactin and IGFBP-1, levels measured in the unstimulated internal controls were subtracted from those measured in the stimulated ESC cultures from MRKHS patients and hysterectomy controls. In cases where two uterine rudiments (left and right side) were available from the same patient, mean prolactin and IGFBP-1 levels for the ESC cultures from the left and the right rudiment were plotted separately in addition.

Quantitative real-time PCR ( $q R T-P C R$ ) analysis of key decidual genes

Key decidual genes were investigated to ascertain whether they were dysregulated in MRKH patients upon decidualization. To this end, primary cultures, passaged once, from controls and MRKH patients remained untreated or were decidualized with $30 \mathrm{nmol} / \mathrm{L} 17 \beta$-estradiol and $1 \mu \mathrm{mol} / \mathrm{L}$ progesterone for 9 days. qRT-PCR analysis as described below was used to determine transcript levels of PRL, IGFBP-1, transcription factor forkhead box 1 (FOXO1), homeobox protein Hox-A10 (HOXA10), CCAAT/enhancer-binding protein beta (C/EBPbeta), PGR, ESR, and proliferation marker Ki-67 (MKI67).

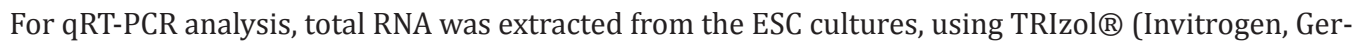
many). Equal amounts of total RNA (2 $\mu \mathrm{g})$ were reverse transcribed using the SuperScript ${ }^{\mathrm{TM}}$ First-Strand synthesis system for RT-PCR (Invitrogen/Fisher Scientific, Schwerte, Germany) and the resulting cDNA was used as a template in qRT-PCR analysis. The gene-specific primer pairs (available on request) were designed using the Primer Blast software. The expression of $h$ L19 (RPL19: Ribosomal Protein 19; Sigma-Aldrich), a human housekeeping gene, was used to normalize for variances in input cDNA. Detection of gene expression was performed with KAPA SYBR® FAST Green (PEQLAB, Erlangen, Germany) and qRT-PCR was performed on the BioRad iCycler iQ ${ }^{\mathrm{TM}}$ Real-Time PCR Detection System (Bio-Rad Laboratories, Munich, Germany). Sample expression levels were expressed as arbitrary units defined by the $\Delta \Delta \mathrm{C}_{\mathrm{T}}$ method as previously described [28]. All measurements were performed in triplicate. Melting curve analysis and agarose gel electrophoresis confirmed amplification specificity.

Statistical analyses

Arithmetic means and standard errors of the mean (SEM) were calculated for the prolactin and IGFBP-1 concentrations in the ESC supernatants from MRKHS patients and hysterectomy controls. Differences in prolactin and IGFBP-1 levels were assessed by the Wilcoxon-Mann-Whitney test and a significance level of $5 \%$ was chosen. All tests were performed and all line graphs created using R version 3.1.3 [29].

For the PCR experiments, statistical analysis was performed by one-way ANOVA followed by Bonferroni's post-hoc test. Statistical significance was observed when $p<0.05$.

\section{Results}

MRKHS patient characteristics

Table 1 shows the baseline demographic and clinical characteristics of MRKHS patients whose uterine rudiments yielded sufficient endometrial tissue to establish ESC cultures for the hormonal stimulation studies, and of the controls. 
Table 1. Baseline demographic and clinical characteristics of MRKHS patients with sufficient endometrial tissue for ESC cultivation, and of controls

\begin{tabular}{|c|c|c|c|c|c|c|c|c|}
\hline Patient & $\begin{array}{l}\text { Age at } \\
\text { surgery } \\
\text { (years) }\end{array}$ & $\begin{array}{l}\text { MRKHS } \\
\text { type }\end{array}$ & Leiomyoma & Adenomyosis & Endometriosis & $\begin{array}{l}\text { Estradiol } \\
\left(p m o l / L^{*}\right)\end{array}$ & $\begin{array}{l}\text { Progesterone } \\
\left(\mathrm{nmol} / \mathrm{L}^{*}\right)\end{array}$ & $\begin{array}{l}\text { Cycle } \\
\text { phase }\end{array}$ \\
\hline M16 & 39 & 2 & Yes & No & No & 157 & 2 & 1 \\
\hline M43 & 19 & 1 & No & $\begin{array}{l}\text { No, but similar } \\
\text { lesions }\end{array}$ & No & 750 & 5.1 & 1 \\
\hline M52 & 29 & 1 & No & No & No & 193 & 3.2 & 1 \\
\hline M56 & 17 & 1 & No & No & No & 113 & 2.2 & 1 \\
\hline M58 & 37 & 1 & No & No & No & 212 & 7.7 & 1 \\
\hline K42 & 38 & $\mathrm{~N} / \mathrm{A}$ & Yes & No & No & 176 & 14.3 & 2 \\
\hline K44 & 39 & $\mathrm{~N} / \mathrm{A}$ & No & No & No & Unknown & Unknown & 2 \\
\hline $\mathrm{K} 45$ & 42 & $\mathrm{~N} / \mathrm{A}$ & No & No & No & 136 & 5.1 & 2 \\
\hline K49 & 44 & $\mathrm{~N} / \mathrm{A}$ & Yes & No & No & Unknown & Unknown & 2 \\
\hline K50 & 42 & $\mathrm{~N} / \mathrm{A}$ & Yes & No & No & 253 & 6.0 & 2 \\
\hline K63 & 40 & $\mathrm{~N} / \mathrm{A}$ & Yes & No & No & Unknown & Unknown & 1 \\
\hline K65 & 46 & $\mathrm{~N} / \mathrm{A}$ & Yes & No & No & Unknown & Unknown & 1 \\
\hline
\end{tabular}

Table 2. Presence of estrogen and progesterone receptors and the proliferation marker Ki-67 (measured using the MIB1 antibody) in endometrial tissue from MRKHS uterine rudiments

\begin{tabular}{|c|c|c|c|c|c|c|c|}
\hline Patient & Cycle phase & $\begin{array}{c}\text { Ki-67 (MIB-1) } \\
\text { epithelium }\end{array}$ & $\begin{array}{c}\text { Ki-67 (MIB-1) } \\
\text { stroma }\end{array}$ & $\begin{array}{c}\text { ESR1 } \\
\text { epithelium } \\
\text { (IRS) }\end{array}$ & $\begin{array}{c}\text { ESR1 } \\
\text { stroma } \\
\text { (IRS) }\end{array}$ & $\begin{array}{c}\text { PGR } \\
\text { epithelium } \\
\text { (IRS) }\end{array}$ & $\begin{array}{c}\text { PGR } \\
\text { stroma } \\
\text { (IRS) }\end{array}$ \\
\hline M16 & Proliferative & $15 \%$ & $0 \%$ & 12 & 12 & 2 & 12 \\
\hline M25 (right) & Secretory & $1 \%$ & $5 \%$ & 12 & 6 & 4 & 4 \\
\hline M25 (left) & Secretory & $0 \%$ & $2 \%$ & 9 & 6 & 3 & 6 \\
\hline M43 (left) & Proliferative & $20 \%$ & $10 \%$ & 8 & 6 & 2 & 6 \\
\hline M43 (right) & Proliferative & $10 \%$ & $0 \%$ & 12 & 3 & 12 & 12 \\
\hline M45 (right) & Proliferative & $90 \%$ & $5 \%$ & 12 & 12 & 12 & 4 \\
\hline M45 (left) & Proliferative & $5 \%$ & $5 \%$ & 12 & 12 & 12 & 9 \\
\hline M50 & Proliferative & $15 \%$ & $1 \%$ & 12 & 12 & 12 & 6 \\
\hline M52 (right) & Proliferative & $2 \%$ & $0 \%$ & 12 & 9 & 8 & 6 \\
\hline M56 & Proliferative & $1 \%$ & $0 \%$ & 12 & 6 & 12 & 4 \\
\hline M58 & Proliferative & $2 \%$ & $0 \%$ & 12 & 6 & 12 & 6 \\
\hline
\end{tabular}

Immunohistochemistry: Differentiation of MRKHS uterine rudiments

As shown in Table 2, 7 of the 8 MRKHS patients who had sufficient endometrium for ESC cultivation were in the proliferative cycle phase and one was in the secretory phase. Only two patients, M25 (secretory phase) and M45 (proliferative phase), exhibited phaseappropriate hormonal responsiveness. The endometrium from patient M25 exhibited low IRS values for the hormone receptors, in particular for PGR, and for the tissue's proliferative capacity as represented by Ki-67, which was an expected finding for the secretory phase. By comparison, the IRS scores for the hormone receptors in the endometrium from patient M45 were higher and were combined with a correlating stronger proliferative capacity as evidenced by a strong Ki-67 reaction in the epithelium of the right uterine rudiment, which was an expected finding for the proliferative phase (Fig. 1). Correspondingly, the M25 and M45 ESC cultures were the only cultures to exhibit proper decidualization as they showed a marked increase in prolactin and IGFBP-1 after hormonal stimulation in vitro (Fig. 3). The remaining 6 MRKHS patients were all in the proliferative phase but although these patients had hormone receptor IRS values similar to those observed for patient M45 this was not accompanied by a high proliferative capacity, as evidenced by a very weak Ki-67 reaction in most cases. The uterine rudiments of these patients thus showed no corresponding hormonal response in vivo and the resulting ESC cultures exhibited no increase in prolactin or IGFBP-1 secretion after hormonal stimulation in vitro. 


\section{Cellular Physiology and Biochemistry

Fig. 1. Immunohistochemistry. Expression of proliferation marker Ki-67 (1a-4a), estrogen receptor (1b-4b), and progesterone receptor (1c-4c) in uterine rudiment tissue from MRKHS patients M45 (proliferative phase) and M25 (secretory phase), both exhibiting phase-appropriate hormonal responsiveness (1a-c and $2 \mathrm{a}-\mathrm{c}$, respectively), and from two nonresponding MRKHS patients (M43 and M58; 3a-c and $4 a-c)$.

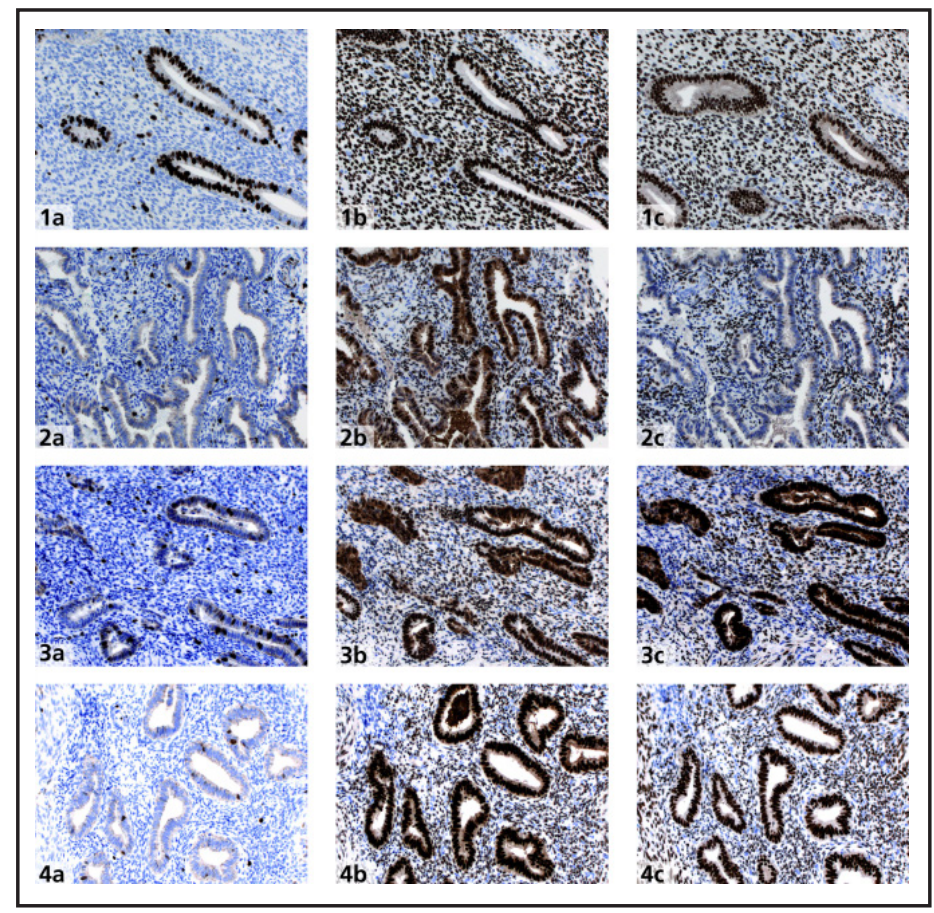

Decidualization of MRKHS versus control ESCs

ESC culture purity and the presence of hormone receptors were ascertained by immunofluorescent staining before hormonal induction of decidualization. On average, purity exceeded $90 \%$ as indicated by the specific endometrial stromal cell marker CD10. Contamination with cells from the underlying myometrium was excluded by staining with the smooth muscle cell marker actin, which revealed positive individual cells in occasional ESC cultures (data not shown). Moreover, ESR1 and PGR were detected in ESC cultures from MRKHS patients and hysterectomy controls $(n=4)$ in varying quantities before hormonal induction.

To investigate further the response of decidual cells from both patient groups, we decidualized purified endometrial stromal cells in the presence of $30 \mathrm{nmol} / \mathrm{L} 17 \beta$-estradiol and 1 $\mu \mathrm{mol} / \mathrm{L}$ progesterone for 9 days. As shown in Fig. 2, decidualization as represented by estrogen and progesterone-induced changes in prolactin and IGFBP-1 levels over a 9-day period in 11 ESC cultures from 8 MRKHS patients were compared with 10 hysterectomy controls. At day 9, mean (SEM) prolactin secretion was significantly lower by $89.0 \%$ in MRKH ESC cultures than in hysterectomy control ESC cultures (3054 (2025) vs. 27663 (6967) pg/mL; Wilcoxon-Mann-Whitney test, $p=0.001$ ), indicating that decidualization was significantly less pronounced in the MRKH ESC cultures (Fig. 2a). Determination of mean (SEM) IGFBP-1 secretion levels at day 9 revealed similar results to those of prolactin secretion and again demonstrated a significant decrease by $99.5 \%$ for MRKHS ESCs vs. hysterectomy controls (1379 (908) vs. 275445 (179321) pg/mL; Wilcoxon-Mann-Whitney test, $p<0.001$; Fig. 2b). For unknown reasons, we observed high values for IGFBP-1 on day 0 , which declined until day 3 but subsequently showed the same tendency as prolactin.

\section{Differences in decidualization among MRKH ESC cultures}

The individual MRKH ESC cultures representing individual patients exhibited marked inter-individual variation in prolactin secretion (Fig. 3). Uterine rudiments from the same patient are identified as "left" and "right".

MRKH ESC cultures M16, M50, M52, and M56 showed poor decidualization, as indicated by low prolactin secretion before day 9 or exhibited prolactin levels near the ELISA's lower detection limit ( $15.6 \mathrm{pg} / \mathrm{mL}$ ). The prolactin levels in the M43 (left and right) and M58 cultures increased slightly over time but their day- 9 average of $88 \mathrm{pg} / \mathrm{mL}$ was still negligible 

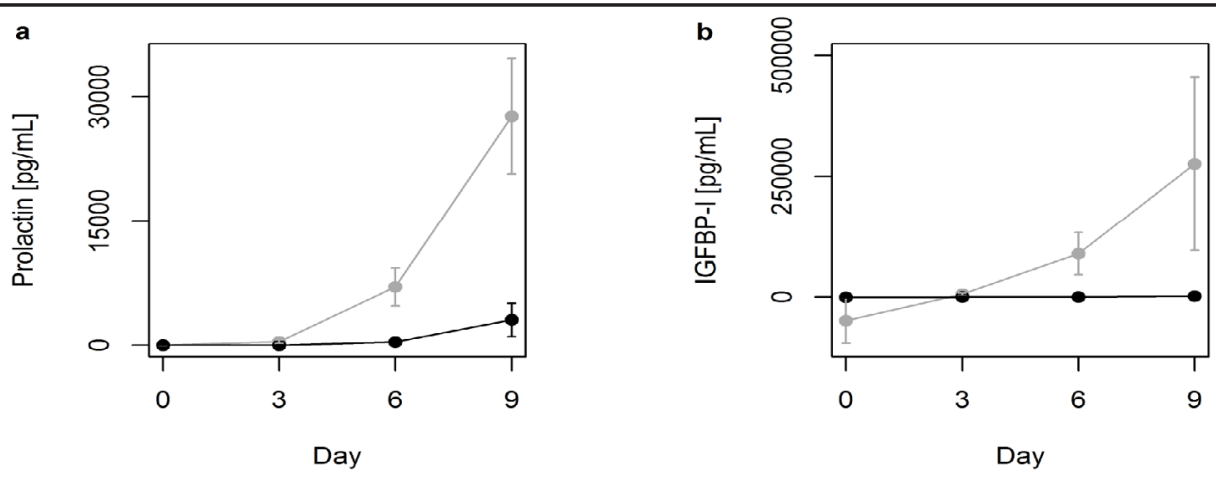

Fig. 2. Hormone-induced decidualization in ESC cultures from MRKHS patients (black) and hysterectomy controls (gray). Solid circles and bars represent means and SEM, respectively, of supernatant concentrations of (a) prolactin and (b) IGFBP-1 measured in duplicate for $11 \mathrm{MRKH}$ ESC cultures and 10 control ESC cultures.
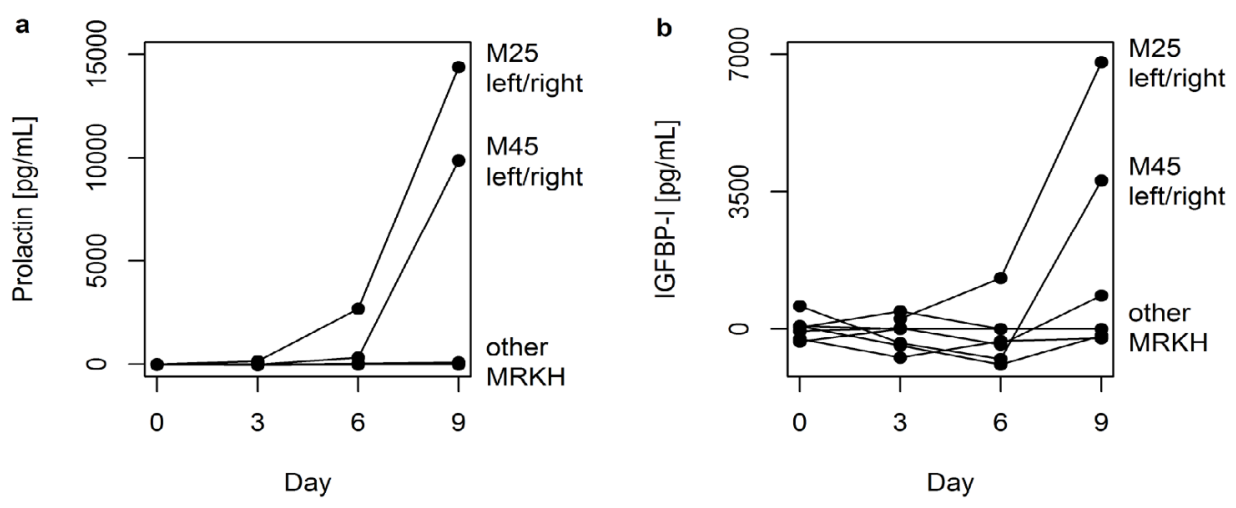

Fig. 3. Hormone-induced decidualization in two MRKH ESC cultures secreting (a) prolactin and (b) IGFBP-1 compared with the other MRKH ESC cultures. Each prolactin and IGFBP-1 concentration represents a single ESC culture or the mean value for two cultures where patients had two rudiments (left and right side).

compared with the levels in the hysterectomy control cultures reported above. By contrast, the M25 (left and right) and M45 (left and right) cultures exhibited marked increases of up to $12123 \mathrm{pg} / \mathrm{mL}$ (day 9). Notably, the final prolactin levels in the M25 (left and right) and M45 (left and right) cultures were within the scattering range of the levels in the hysterectomy control cultures (Fig. 3a). It could also be shown that in patients with two uterine rudiments, i.e. one on the left and one on the right side, intra-individual variation in ESC prolactin levels was low while inter-individual variability was considerable. IGFBP-1 levels indicated the same tendency (Fig. 3b); intra-individual variation was seen between the left and right rudiment levels in M25.

\section{MRKHS phenotype and ESC response to hormone stimulation}

We examined whether the observed variability in hormone-stimulated prolactin and IGFBP-1 secretion in MRKH ESC cultures could be explained by the different manifestations of MRKHS (Table 1).

The observed differences in prolactin secretion showed no clear correlation with type 1 or type 2 MRKHS. However, the two type-2 MRKHS patients were among those with the lowest prolactin secretion in the MRKHS group. Comparison of the blood hormone profiles taken one day before surgery revealed remarkable findings in the case of MRKHS patient M25. In addition to having the type-1 MRKHS phenotype, this patient had a hormone-producing benign ovarian cyst on her left ovary, leading to elevated blood estradiol, progesterone, and 
Fig. 4. qRT-PCR analysis of key decidual genes. Primary cultures, passaged once, from 3 controls and 11 MRKH patients remained untreated (Un) or were decidualized (D) with $30 \mathrm{nmol} / \mathrm{L} 17 \beta$-estradiol and $1 \mu \mathrm{mol} / \mathrm{L}$ progesterone for 9 days. Transcript levels were determined for the following genes (from top left to bottom right): prolactin $(P R L)$, insulin-like growth factor-binding protein 1 (IGFBP-1), transcription factor forkhead box 1 (FOXO1), homeobox protein Hox-A10 (HOXA10), CCAAT/enhancer-binding protein beta $(C)$ EBPbeta), progesterone receptor $(P G R)$, estrogen receptor $(E S R)$, and proliferation marker Ki-67 (MKI67). Note the logarithmic y-axes. Statistical significance $(\mathrm{p}<0.05)$ was observed as indicated by the letters a, c, d, e, and f: (a) untreated control (ConUn) vs. decidualized control (Con-D), (c) Con-Un vs. decidualized MRKH (MRKHD), (d) Con-D vs. untreated MRKH (MRKH-Un), (e) Con-D vs. MRKH-D, and (f) MRKHUn vs. MRKH-D). Significance was not observed for (b) ConUn vs. MRKH-Un.
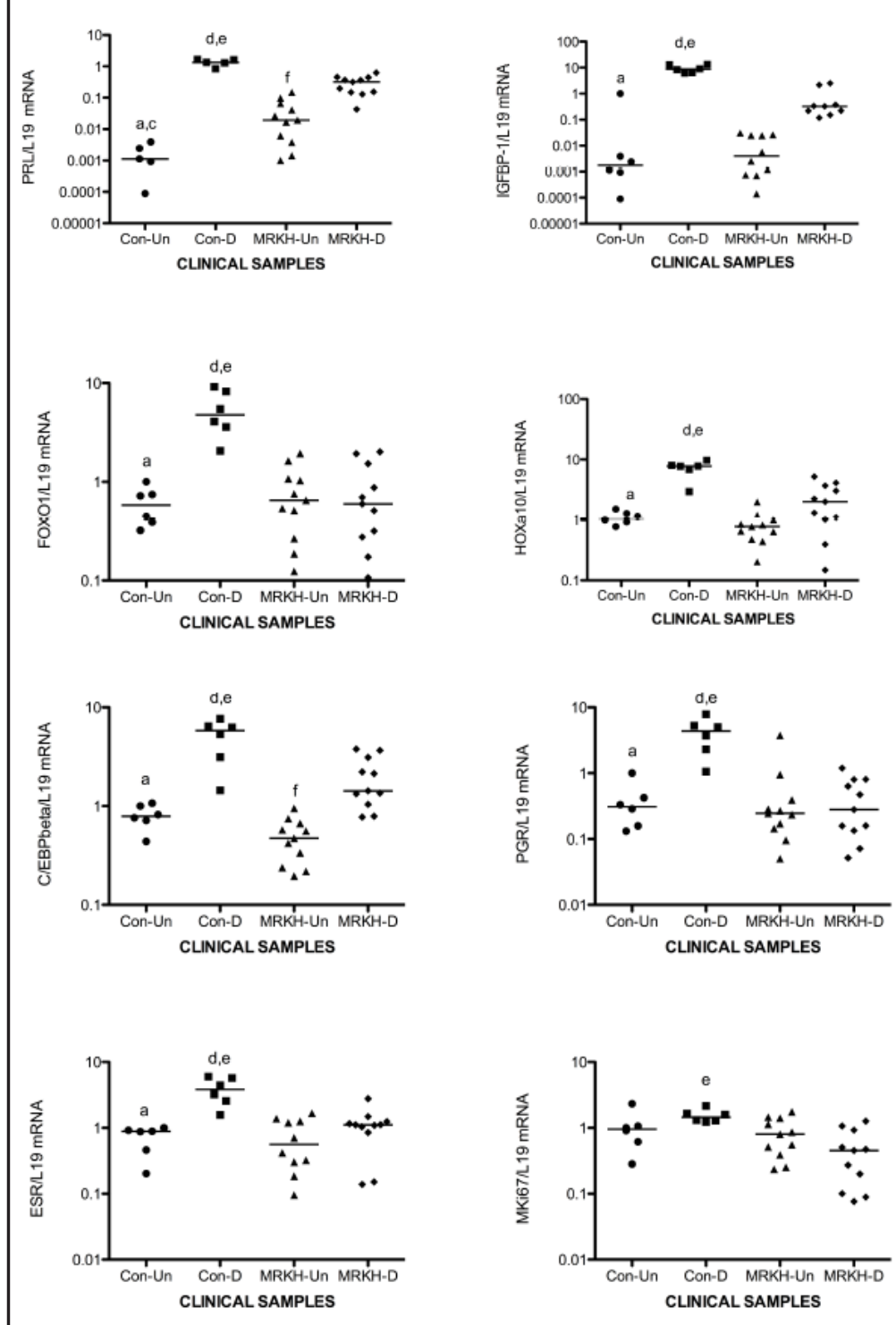

androgen levels. Moreover, M25 (left and right) was among the MRKH ESC cultures exhibiting high mean prolactin levels and, in fact, produced $14379 \mathrm{pg} / \mathrm{mL}$ (day 9), the highest mean prolactin levels of all MRKH ESC cultures in this study. Taking into account secondary diagnoses such as leiomyomas, adenomyosis, and endometriosis, which may affect endometrial function, we found that patient M25 had adenomyosis and patient M45 had adenomyosis and endometriosis and that these were the only two MRKH ESC cultures in which hormoneinduced prolactin and IGFBP-1 secretion increased markedly over time (Fig. 3).

qRT-PCR analysis of key decidual genes

To test further the assertion that decidualizing ESCs from MRKH patients were impaired, we investigated key decidual genes in primary cultures. To this end primary cultures (3 controls and 11 MRKHS patients) were decidualized as above, and mRNA was extracted and subjected to qRT-PCR. Figure 4 summarizes the qRT-PCR analysis of the transcript levels of PRL, IGFBP-1, FOXO1, HOXA10, C/EBPbeta, PGR, ESR, and MKI67. Upon treatment with estrogen and progesterone decidualization was apparent in the control group, which is in keeping with previous findings [28]. Surprisingly, decidualization was also observed in the 


\section{Cellular Physiology Cell Physiol Biochem 2017;41:1083-1097 \\ \begin{tabular}{ll|l} 
DOI: 10.1159/000464116 & $\begin{array}{l}\text { O 2017 The Author(s). Published by S. Karger AG, Basel } \\
\text { www.karger.com/cpb }\end{array}$ \\
\cline { 2 - 3 }
\end{tabular} \\ Brucker et al.: Decidualization is Impaired in ESCs}

MRKH group, but transcript levels were significantly lower than in the control group. Taken together, these results indicate that MRKH patients have an aberrant hormonal responsiveness resulting in impaired endometrial decidualization.

\section{Discussion}

The present study is, to our knowledge, the first to investigate primary ESC cultures from MRKHS patients in a functional approach by measuring decidualization to indirectly elucidate the role of hormone receptors in the etiology of MRKHS. Earlier studies have indicated that, potentially, hormone receptors may be dysfunctional in patients with the syndrome $[2,13]$. A recent whole-genome analysis of our MRKHS patient population revealed overexpression of ESR1 and PGR in tissue from uterine rudiments [13]. A subsequent histological and immunohistochemical study revealed that the proliferative capacity of endometrium from MRKHS patients was significantly reduced [2]. Taken together, these two studies suggested that potentially a functional defect in ESR1 and PGR signaling could be responsible for the reduced proliferative capacity and the developmental defects associated with the syndrome. Our current approach to testing ESR1 and PGR function in MRKHS patients utilized the physiological conversion of endometrial stromal fibroblasts to secretory decidual cells in a process known as decidualization, when the endometrium prepares for embryo implantation during the second phase of the menstrual cycle $[18,19]$. In vitro decidualization is induced by estrogen and progesterone via their respective cognate nuclear receptors [3032]. Our present study demonstrated that control ESC cultures from hysterectomy patients showed estrogen and progesterone-induced prolactin and IGFBP-1 secretion, resulting in markedly increased levels at day 9 while MRKH ESC cultures exhibited significantly lower mean increases in prolactin and IGFBP-1 levels as well as decreased transcript levels of the key decidual genes PRL, IGFBP-1, FOXO1, HOXA10, C/EBPbeta, PGR, ESR, and MKI67. Indeed, seven of the eleven MRKH ESC cultures that we were able to investigate showed almost no increase in prolactin or IGFBP-1 levels; only four cultures from two patients who each had two uterine rudiments exhibited marked increases in prolactin and IGFBP-1 secretion in response to hormone stimulation. However, these four MRKH cultures from patients M25 (left and right) and M45 (left and right) warrant separate discussion because both MRKHS patients had relevant additional genital tract disease, as specified below.

The inability of seven verified MRKH ESC cultures to undergo decidualization could indicate a lack of hormone responsiveness and can indirectly be considered indicative of functional deficiency of ESR1 and PGR activity. Moreover, it is well established that sex steroid hormones and their receptors are involved in the development of the female genitalia and that any changes in effect or loss of function can lead to a wide variety of developmental defects such as those observed in MRKHS. Such negative impacts on female genital tract development are well documented, e.g., for the synthetic estrogen diethylstilbestrol (DES), and include, inter alia, malformations of the upper genital tract [33]. The role of hormone receptors in the proper development of the female reproductive tract has been investigated in several estrogen receptor $(E R)$ and $P G R$ knockout mouse models. The importance of ESR1 is evidenced by infertility and the presence of hypoplastic uteri in ESR1 knockout female mice $[34,35]$. PGR knockout female mice exhibited similar deficiencies accompanied by implantation defects and the absence of ESC decidualization after progesterone stimulation [32, 36]. Moreover, whether other steroid hormones such as testosterone, mineralocorticoids or glucocorticoids are involved, is warranted given its role in decidualization [37, 38].

Moreover, the importance of steroid hormones, such as estrogen and progesterone, and their receptors for the functioning and health of the adult uterus has been shown in numerous studies investigating endometriosis [39-41], leiomyomas [42-44], endometrial cancer $[45,46]$, and recurrent pregnancy loss $[47,48]$.

Progesterone controls a matrix of reproductive events including ovulation, embryo implantation, decidualization, and menstruation. A recent microarray study comparing puri- 
fied eutopic endometrial stromal cells from patients with and without endometriosis upon progesterone stimulation revealed that aberrant gene expression is not confined to progesterone response but is also evident in unstimulated cultures [49]. A characteristic of eutopic endometrium in patients with endometriosis is resistance to progesterone signaling, or "progesterone resistance".

Both PGR isoforms derive from different promoter usage in a single gene, but PGR-B differs from PGR-A in that it contains an additional 164 amino acids at the amino-terminus [50]. While PGR-A and -B display identical hormone- and DNA-binding affinities, their actions are divergent. A number of alternatively transcribed, translated, or spliced isoforms have been described, including PGR-C, -M, or -S; however, it is unclear if these truncated PGR variants are physiologically active in vivo. PGR contains defined sequences, termed nuclear import and export signals, which enables the receptor to shuttle actively between the nuclear and cytoplasmic compartments. The unliganded receptor is assembled in large multi-subunit complexes that contain various heat shock proteins (e.g., HSP70) and immunophilins (e.g., FKBP51 and FKBP52) [51]. These chaperone proteins maintain the receptor in a conformation state that allows hormone binding and play a critical role in the dynamic shuttling of the receptor. Progesterone can move through the cell membrane and trigger a conformational change in PGR. This in turn results in dissociation from the chaperone proteins, dimerization, and binding of the receptor to specific DNA recognition sequences in the promoters of target genes, leading to activation or repression of transcription. Whether these processes are deregulated in MRKHS remains to be defined.

Our observations indicate that the basal transcriptome in the cohort of samples is perturbed. Impaired signaling from endometrium from MRKH patients may be due to direct impaired-progesterone signaling resulting in failure of the endometrium to undergo hormoneinduced decidualization, or indirect effects could point to aberrant epigenetic regulation that affects the chromatin landscape, leading to indirect steroidal signaling. Further studies are warranted to prove this hypothesis.

In our study, the four MRKHS ESC cultures producing remarkably high prolactin levels originated from two MRKHS patients with secondary diagnoses of adenomyosis, hormoneproducing ovarian cyst, and/or endometriosis, all of which are known to be associated with altered steroid hormone levels or effects. We therefore assume that these two MRKHS patients carried additional, adenomyosis and/or endometriosis related changes in the signaling pathways involved.

Thus, these secondary disorders may have a partially compensatory effect, at least with regard to the decidualization process in the uterine rudiments of adult MRKHS patients. However, adenomyosis and/or endometriosis are rare exceptions in MRKHS patients and do not necessarily occur in all uterine rudiments containing functional endometrium [52-60]. Another possible reason for the observed differences in prolactin and IGFBP-1 secretion between the ESC cultures from different MRKHS patients could also be the varying primary differentiation of the endometrial tissue in the respective MRKHS uterine rudiments of these patients [2]. Indeed, only the uterine rudiments of the two MRKHS patients whose ESC cultures exhibited a marked increase in decidualization markers also showed signs of appropriate hormonal responsiveness in vivo, as deduced from the correlation between the respective hormone receptor and proliferation status of the uterine rudiment tissue, and the corresponding cycle phase at the time of surgery.

The uterine rudiment tissues of the 6 MRKHS patients whose ESC cultures exhibited no sign of decidualization were found to be in the proliferative phase of the cycle but possessed no accompanying high proliferative capacity as represented by the proliferation marker Ki-67. As mentioned above, the decrease in proliferative capacity of MRKHS-derived endometrium during the proliferative cycle phase could be a direct consequence of impaired hormone receptors, among other things.

Limitations of the present study include the in vitro approach as such, which may not fully replicate the in vivo situation. Moreover, the yield of endometrial tissue was low due to the nature of the disorder and our MRKHS patient population was a convenience sample

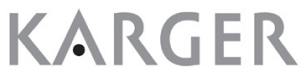


rather than a randomized sample because of the low incidence of the disorder [10, 61]. Finally, it must be emphasized that receptor functionality was not evaluated directly in our study. Lack of hormone responsiveness does not necessarily imply receptor dysfunction. The direct role of receptor changes in many instances is unclear and there is increasing evidence that post-receptor epigenetic changes as well as involvement of microRNAs or any other epigenetic factors may play a role in this pathology [30].

Progesterone resistance due to several potential mechanisms has been described in diseases like endometriosis [30]. On the other hand, partial progesterone resistance is reminiscent of the fetal and neonatal situation and seems to persist into adolescence, leading to major obstetrical problems. Preconditioning of the uterus in response to cyclic menstruation during adolescence appears to be a prerequisite to achieve full endometrial responsiveness to hormones [62]. As this effect is missing in MRKH syndrome this might be another reason for the immature endometrium found in the uterine rudiments.

Mouse models have demonstrated that the absence of ESR1 or PGR, and the resulting loss of hormone receptor function, can lead to malformations of the female genital organs, in particular to a hypoplastic uterus or vagina [34, 35]. Interestingly, secondary disorders such as adenomyosis or endometriosis, which were present in two of our MRKHS patients, may apparently affect pathways similar to those suspected to play a role in MRKHS itself, as evidenced by hormone-induced decidualization occurring only in these two exceptional cases. Hence, on the one hand our findings support the hypothesis that similar signaling cascades are involved both in the development of the female genital tract and in adult uterine function during the processes of the menstrual cycle. On the other hand, the observed differences in prolactin and IGFBP-1 secretion between ESC cultures from different MRKHS patients may result from primary differences in endometrial hormonal responsiveness, which in turn may reflect the variation in syndrome severity. Of course, within the limitations of our methodological approach, we cannot rule out completely that, in addition to functionally impaired hormone receptors, other mechanisms and genes might also be affected. However, our results suggest the involvement of the hormone receptors ESR1 and PGR in MRKHS. In addition, in-vitro decidualization of primary MRKH ESC cultures provides a powerful tool for further research into MRKHS, and especially into pathways involved in the syndrome.

In conclusion, our present study provides novel evidence that lack of hormone responsiveness plays a role in the onset of MRKHS.

\section{Acknowledgements}

The authors gratefully acknowledge all patients whose data were used in this study. We also thank Sabine Hofmeister, who provided excellent technical assistance with the cell cultures, immunofluorescent staining, and prolactin determinations. We also acknowledge support by the Open Access Publishing Fund of the University of Tübingen.

K.R. acknowledges the receipt of time-limited PATE and TÜFF research fellowship grants awarded to her by the "Fortüne" intramural research funding program of the University of Tübingen.

There was no funding for this work.

\section{Disclosure Statement}

The authors declare that they have no conflict of interest.

\section{References}

1 Hauser GA, Schreiner WE: [Mayer-Rokitansky-Kuester syndrome. Rudimentary solid bipartite uterus with solid vagina]. Schweiz Med Wochenschr 1961;91:381-384. 


\section{Cellular Physiology Cell Physiol Biochem 2017;41:1083-1097 \begin{tabular}{l|l|l} 
and Biochemistry Published onlıne: February 27, 2017 & $\begin{array}{l}\text { (c) } 2017 \text { The Author(s). Published by S. Karger AG, Basel } \\
\text { www.karger.com/cpb }\end{array}$ \\
\hline
\end{tabular}

2 Rall K, Barresi G, Wallwiener D, Brucker SY, Staebler A: Uterine rudiments in patients with Mayer-Rokitansky-Küster-Hauser syndrome consist of typical uterine tissue types with predominantly basalis-like endometrium. Fertil Steril 2013;99:1392-1399.

-3 Marsh CA, Will MA, Smorgick N, Quint EH, Hussain H, Smith YR: Uterine remnants and pelvic pain in females with Mayer-Rokitansky-Küster-Hauser syndrome. J Pediatr Adolesc Gynecol 2013;26:199-202. van Lingen BL, Reindollar RH, Davis AJ, Gray MR: Molecular genetic analysis of the PAX2 gene in patients with congenital absence of uterus and vagina. (Abstract). Fertil Steril 1998;70:S402.

5 van Lingen BL, Reindollar RH, Davis AJ, Gray MR: Further evidence that the WT1 gene does not have a role in the development of the derivatives of the müllerian duct. Am J Obstet Gynecol 1998;179:597-603. Klipstein S, Bhagavath B, Topipat C, Sasur L, Reindollar RH, Gray MR: The N314D polymorphism of the GALT gene is not associated with congenital absence of the uterus and vagina. Mol Hum Reprod 2003;9:171-174.

7 Timmreck LS, Gray MR, Handelin B, Allito B, Rohlfs E, Davis AJ, Gidwani G, Reindollar RH: Analysis of cystic fibrosis transmembrane conductance regulator gene mutations in patients with congenital absence of the uterus and vagina. Am J Med Genet A 2003;120A:72-76.

8 Burel A, Mouchel T, Odent S, Tiker F, Knebelmann B, Pellerin I, Guerrier D: Role of HOXA7 to HOXA13 and PBX1 genes in various forms of MRKH syndrome (congenital absence of uterus and vagina). J Negat Results Biomed 2006;5:4.

-9 Oppelt P, Strissel PL, Kellermann A, Seeber S, Humeny A, Beckmann MW, Strick R: DNA sequence variations of the entire anti-Mullerian hormone (AMH) gene promoter and $\mathrm{AMH}$ protein expression in patients with the Mayer-Rokitanski-Kuster-Hauser syndrome. Hum Reprod 2005;20:149-157.

10 Morcel K, Camborieux L, Guerrier D: Mayer-Rokitansky-Küster-Hauser (MRKH) syndrome. Orphanet J Rare Dis 2007;2:13.

11 Ravel C, Lorenco D, Dessolle L, Mandelbaum J, McElreavey K, Darai E, Siffroi JP: Mutational analysis of the WNT gene family in women with Mayer-Rokitansky-Kuster-Hauser syndrome. Fertil Steril 2009;91:16041607.

12 Ekici AB, Strissel PL, Oppelt PG, Renner SP, Brucker S, Beckmann MW, Strick R: HOXA10 and HOXA13 sequence variations in human female genital malformations including congenital absence of the uterus and vagina. Gene 2013;518:267-272.

13 Rall K, Barresi G, Walter M, Poths S, Haebig K, Schaeferhoff K, Schoenfisch B, Riess O, Wallwiener D, Bonin $\mathrm{M}$, Brucker S: A combination of transcriptome and methylation analyses reveals embryologically-relevant candidate genes in MRKH patients. Orphanet J Rare Dis 2011;6:32.

14 Ludwig KS: The Mayer-Rokitansky-Küster syndrome. An analysis of its morphology and embryology. Part II: Embryology. Arch Gynecol Obstet 1998;262:27-42.

15 Fraser IS, Baird DT, Hobson BM, Michie EA, Hunter W: Cyclical ovarian function in women with congenital absence of the uterus and vagina. J Clin Endocrinol Metab 1973;36:634-637.

-16 Shokeir MH: Aplasia of the Müllerian system: evidence for probable sex-limited autosomal dominant inheritance. Birth Defects Orig Artic Ser 1978;14:147-165.

17 Folch M, Pigem I, Konje JC: Müllerian agenesis: etiology, diagnosis, and management. Obstet Gynecol Surv 2000;55:644-649.

18 Dunn CL, Kelly RW, Critchley HO: Decidualization of the human endometrial stromal cell: an enigmatic transformation. Reprod Biomed Online 2003;7:151-161.

19 Gellersen B, Brosens IA, Brosens JJ: Decidualization of the human endometrium: mechanisms, functions, and clinical perspectives. Semin Reprod Med 2007;25:445-453.

20 Bell SC: The insulin-like growth factor binding proteins--the endometrium and decidua. Ann N Y Acad Sci 1991;622:120-137.

-21 Brosens JJ, Hayashi N, White JO: Progesterone receptor regulates decidual prolactin expression in differentiating human endometrial stromal cells. Endocrinology 1999;140:4809-4820.

22 Daly DC, Maslar IA, Riddick DH: Prolactin production during in vitro decidualization of proliferative endometrium. Am J Obstet Gynecol 1983;145:672-678.

-23 Gellersen B, Brosens J: Cyclic AMP and progesterone receptor cross-talk in human endometrium: a decidualizing affair. J Endocrinol 2003;178:357-372.

24 Maslar IA, Riddick DH: Prolactin production by human endometrium during the normal menstrual cycle. Am J Obstet Gynecol 1979;135:751-754. 


\section{Cellular Physiology Cell Physiol Biochem 2017;41:1083-1097 \begin{tabular}{ll|l|l|l} 
DOI: 10.1159/000464116 & 2017 The Author(s). Published by S. Karger AG, Basel \\
and Biochemistry & Publisned online: February 27, 2017 www.karger.com/cpb
\end{tabular} \\ Brucker et al.: Decidualization is Impaired in ESCs}

-25 Fluhr H, Krenzer S, Deperschmidt M, Zwirner M, Wallwiener D, Licht P: Human chorionic gonadotropin inhibits insulin-like growth factor-binding protein-1 and prolactin in decidualized human endometrial stromal cells. Fertil Steril 2006;86:236-238.

-26 von Wolff M, Stieger S, Lumpp K, Bucking J, Strowitzki T, Thaler CJ: Endometrial interleukin-6 in vitro is not regulated directly by female steroid hormones, but by pro-inflammatory cytokines and hypoxia. Mol Hum Reprod 2002;8:1096-1102.

-27 Remmele W, Stegner HE: [Recommendation for uniform definition of an immunoreactive score (IRS) for immunohistochemical estrogen receptor detection (ER-ICA) in breast cancer tissue]. Pathologe 1987;8:138-140.

28 Salker M, Teklenburg G, Molokhia M, Lavery S, Trew G, Aojanepong T, Mardon HJ, Lokugamage AU, Rai R, Landles C, Roelen BA, Quenby S, Kuijk EW, Kavelaars A, Heijnen CJ, Regan L, Macklon NS, Brosens JJ: Natural selection of human embryos: impaired decidualization of endometrium disables embryo-maternal interactions and causes recurrent pregnancy loss. PLoS One 2010;5:e10287.

29 R Core Team: R: A Language and Environment for Statistical Computing. Vienna, Austria, R Foundation for Statistical Computing, 2014.

-30 Al-Sabbagh M, Lam EW, Brosens JJ: Mechanisms of endometrial progesterone resistance. Mol Cell Endocrinol 2012;358:208-215.

31 Brar AK, Frank GR, Kessler CA, Cedars MI, Handwerger S: Progesterone-dependent decidualization of the human endometrium is mediated by cAMP. Endocrine 1997;6:301-307.

-32 Lydon JP, DeMayo FJ, Funk CR, Mani SK, Hughes AR, Montgomery CA, Jr., Shyamala G, Conneely OM, O'Malley BW: Mice lacking progesterone receptor exhibit pleiotropic reproductive abnormalities. Genes Dev 1995;9:2266-2278.

-33 Kaufman RH, Adam E: Genital tract anomalies associated with in utero exposure to diethylstilbestrol. Isr J Med Sci 1978;14:353-362.

-34 Lubahn DB, Moyer JS, Golding TS, Couse JF, Korach KS, Smithies O: Alteration of reproductive function but not prenatal sexual development after insertional disruption of the mouse estrogen receptor gene. Proc Natl Acad Sci U S A 1993;90:11162-11166.

35 Couse JF, Korach KS: Estrogen receptor null mice: what have we learned and where will they lead us? Endocr Rev 1999;20:358-417.

-36 Mulac-Jericevic B, Conneely OM: Reproductive tissue-selective actions of progesterone receptors. Ernst Schering Res Found Workshop 2005:19-37.

-37 Kuroda K, Venkatakrishnan R, Salker MS, Lucas ES, Shaheen F, Kuroda M, Blanks A, Christian M, Quenby S, Brosens JJ: Induction of 11beta-HSD 1 and activation of distinct mineralocorticoid receptor- and glucocorticoid receptor-dependent gene networks in decidualizing human endometrial stromal cells. Mol Endocrinol 2013;27:192-202.

-38 Cloke B, Huhtinen K, Fusi L, Kajihara T, Yliheikkila M, Ho KK, Teklenburg G, Lavery S, Jones MC, Trew G, Kim JJ, Lam EW, Cartwright JE, Poutanen M, Brosens JJ: The androgen and progesterone receptors regulate distinct gene networks and cellular functions in decidualizing endometrium. Endocrinology 2008;149:44624474 .

39 Jänne 0, Kauppila A, Kokko E, Lantto T, Rönnberg L, Vihko R: Estrogen and progestin receptors in endometriosis lesions: comparison with endometrial tissue. Am J Obstet Gynecol 1981;141:562-566.

40 Jiang J, Wu RF, Wang ZH, Sun HC, Xu Z, Xiu HM: Effect of mifepristone on estrogen and progesterone receptors in human endometrial and endometriotic cells in vitro. Fertil Steril 2002;77:995-1000.

-41 Bulun SE, Cheng YH, Yin P, Imir G, Utsunomiya H, Attar E, Innes J, Julie Kim J: Progesterone resistance in endometriosis: link to failure to metabolize estradiol. Mol Cell Endocrinol 2006;248:94-103.

-42 Brandon DD, Bethea CL, Strawn EY, Novy MJ, Burry KA, Harrington MS, Erickson TE, Warner C, Keenan EJ, Clinton GM: Progesterone receptor messenger ribonucleic acid and protein are overexpressed in human uterine leiomyomas. Am J Obstet Gynecol 1993;169:78-85.

43 Palomba S, Sena T, Morelli M, Noia R, Zullo F, Mastrantonio P: Effect of different doses of progestin on uterine leiomyomas in postmenopausal women. Eur J Obstet Gynecol Reprod Biol 2002;102:199-201.

-44 Moravek MB, Yin P, Ono M, Coon JSt, Dyson MT, Navarro A, Marsh EE, Chakravarti D, Kim JJ, Wei JJ, Bulun SE: Ovarian steroids, stem cells and uterine leiomyoma: therapeutic implications. Hum Reprod Update 2015;21:1-12. 


\section{Cellular Physiology Cell Physiol Biochem 2017;41:1083-1097 \begin{tabular}{ll|l} 
Ond 2017 The Author(s). Published by S. Karger AG, Basel \\
and Biochemistry
\end{tabular}

45 Beral V, Bull D, Reeves G, Million Women Study C: Endometrial cancer and hormone-replacement therapy in the Million Women Study. Lancet 2005;365:1543-1551.

-46 Utsunomiya H, Suzuki T, Kaneko C, Takeyama J, Nakamura J, Kimura K, Yoshihama M, Harada N, Ito K, Konno R, Sato S, Okamura K, Sasano H: The analyses of 17beta-hydroxysteroid dehydrogenase isozymes in human endometrial hyperplasia and carcinoma. J Clin Endocrinol Metab 2001;86:3436-3443.

47 Norwitz ER, Schust DJ, Fisher SJ: Implantation and the survival of early pregnancy. N Engl J Med 2001;345:1400-1408.

-48 Carranza-Lira S, Blanquet J, Tserotas K, Calzada L: Endometrial progesterone and estradiol receptors in patients with recurrent early pregnancy loss of unknown etiology--preliminary report. Med Sci Monit 2000;6:759-762.

49 Aghajanova L, Tatsumi K, Horcajadas JA, Zamah AM, Esteban FJ, Herndon CN, Conti M, Giudice LC: Unique transcriptome, pathways, and networks in the human endometrial fibroblast response to progesterone in endometriosis. Biol Reprod 2011;84:801-815.

-50 Kastner P, Krust A, Turcotte B, Stropp U, Tora L, Gronemeyer H, Chambon P: Two distinct estrogen-regulated promoters generate transcripts encoding the two functionally different human progesterone receptor forms A and B. ЕМBO J 1990;9:1603-1614.

51 Tranguch S, Wang H, Daikoku T, Xie H, Smith DF, Dey SK: FKBP52 deficiency-conferred uterine progesterone resistance is genetic background and pregnancy stage specific. J Clin Invest 2007;117:1824-1834.

52 Chun S, Kim YM, Ji YI: Uterine adenomyosis which developed from hypoplastic uterus in postmenopausal woman with mayer-rokitansky-kuster-hauser syndrome: a case report. J Menopausal Med 2013;19:135138.

-53 Enatsu A, Harada T, Yoshida S, Iwabe T, Terakawa N: Adenomyosis in a patient with the Rokitansky-KusterHauser syndrome. Fertil Steril 2000;73:862-863.

54 Yan CM, Mok KM: Uterine fibroids and adenomyosis in a woman with Rokitansky-Kuster-Hauser syndrome. J Obstet Gynaecol 2002;22:561-562.

55 Hall-Craggs MA, Williams CE, Pattison SH, Kirkham AP, Creighton SM: Mayer-Rokitansky-Kuster-Hauser syndrome: diagnosis with MR imaging. Radiology 2013;269:787-792.

-56 Troncon JK, Zani AC, Vieira AD, Poli-Neto OB, Nogueira AA, Rosa ESJC: Endometriosis in a patient with mayer-rokitansky-küster-hauser syndrome. Case Rep Obstet Gynecol 2014;2014:376231.

57 Will MA, Marsh CA, Smorgick N, Smith YR, Quint EH: Surgical pearls: laparoscopic removal of uterine remnants in patients with Mayer-Rokitansky-Küster-Hauser syndrome. J Pediatr Adolesc Gynecol 2013;26:224-227.

58 Yan L, Zhao X, Qin X: MRKH syndrome with endometriosis: case report and literature review. Eur J Obstet Gynecol Reprod Biol 2011;159:231-232.

-59 Parkar RB, Kamau WJ: Images in endoscopy. Laparoscopic excision of bilateral functioning noncommunicating and rudimentary uterine horns in a patient with Mayer-Rokitansky-Küster-Hauser syndrome and pelvic endometriosis. J Minim Invasive Gynecol 2009;16:522-524.

-60 Mok-Lin EY, Wolfberg A, Hollinquist H, Laufer MR: Endometriosis in a patient with Mayer-RokitanskyKüster-Hauser syndrome and complete uterine agenesis: evidence to support the theory of coelomic metaplasia. J Pediatr Adolesc Gynecol 2010;23:e35-37.

61 ACOG Committee on Adolescent Health Care: ACOG Committee Opinion No. 355: Vaginal agenesis: diagnosis, management, and routine care. Obstet Gynecol 2006;108:1605-1609.

62 Brosens I, Benagiano G, Brosens JJ: The potential perinatal origin of placentation disorders in the young primigravida. Am J Obstet Gynecol 2015;212:580-585. 